\title{
The Functional outcome following anterior cervical discectomy and fusion for single level cervical degenerative disc disease: a prospective single institutional study
}

\author{
Somraj Lamichhane $M S^{1}$, Sujata Panta $M B B S^{2}$, Devendra Acharya $M S^{3}$ \\ 1,2,3 Department of Neurosurgery, College of Medical Sciences Teaching Hospital, Nepal
}

Date of submission: $28^{\text {th }}$ April 2020

Date of acceptance: $16^{\text {th }}$ July 2020

Date of publication: $12^{\text {th }}$ August 2020

\section{Abstract}

Introduction: Cervical degenerative disc diseases leading to cervical spondylotic myelopathy (CSM) is one the most common cause of disability in elderly population that progresses with age with continuation of degree of degeneration.

Objective: To assess the functional outcome following ACDF in single-level cervical degenerative disc disease in terms of improvement in the mJOA scoring system and postoperative complications.

Materials and methods: Eighteen patients with single level cervical degenerative disc diseases who presented at the college of medical sciences from May 2018 to October 2019 fulfilling the inclusion criteria (single-level cervical degenerative disc disease with age between 40 to 70 years with progressive neurological deficits, features of cervical spondylotic myelopathy and patients with mild grade who failed four weeks of conservative treatment and progressed to moderate or severe grades) were included in the study. All patients underwent Anterior Cervical Discectomy and Fusion (ACDF); with tricortical iliac crest graft with cervical plate and screws in 13 patients and polyether ether ketone (PEEK) cage placement in five patients. Patients were assessed using mJOA scoring system and graded into mild, moderate and severe myelopathy. Post-operatively patients were assessed for improvement in terms of mJOA scores at four weeks and three months follow-up. They were also assessed for development of any post-operative complications and documented accordingly. Statistical analysis was done using the Statistical Package for the Social Sciences version 20 software.

Results: Out of 18 patients, at the time of presentation 12 were in moderate grade and six were in severe grade. During subsequent follow up at four weeks and three months, patients showed progressive improvement. 15 patients improved to mild grade while two remained in moderate grade and one in severe grade during three months postoperative assessment. One patient each developed dysphagia, hoarseness and superficial wound infection that were managed conservatively.

Conclusion: Anterior cervical discectomy and fusion is one of the effective and safe treatments for single-level degenerative cervical disc disease associated with cervical spondylotic myelopathy with minimal complications.

Key words: Anterior cervical discectomy and fusion (ACDF), Cervical spondylotic myelopathy, Modified Japanese Orthopedic association Score

\section{Introduction}

\section{Access this article online}

Website: https://www.nepjol.info/index.php/NJN

DOI: https://doi.org/10.3126/njn.v17i2.30164

HOW TO CITE

Lamichhane S, Panta S, Acharya D. The Functional outcome

following anterior cervical discectomy and fusion for single

level cervical degenerative disc disease: a prospective single

institutional study. NJNS. 2020;17(2):42-47

${ }^{1}$ ORCID id: 0000-0002-0978-9509

${ }^{2}$ ORCID id: 0000-0002-6578-2889

${ }^{3}$ ORCID id: 0000-0001-5747-1952
$\mathrm{D}$ egenerative disc disease (DDD) of the cervical spine, included under the spectrum of cervical spondylosis

Address for correspondence:

Dr. Somraj Lamichhane

Ratnanagar-13, Chitwan, Nepal

Contact number: +977-9841508146

E-mail: tandisom@gmail.com

Copyright (C) 2020 Nepalese Society of Neurosurgeons (NESON)

ISSN: 1813-1948 (Print), 1813-1956 (Online)

(i) \& This work is licensed under a Creative Commons Attribution-Non Commercial 4.0 International License. 
(CS), is the most common acquired cause of disability in patients older than 55 years that gradually progresses with age. ${ }^{1,2}$ Cervical spondylosis or cervical DDD may produce several clinical features: myeloradiculopathy due to nerve root compression, pain and paresthesia in the neck without radicular pain, and cervical spondylotic myelopathy (CSM) due to spinal cord compression. ${ }^{3} \mathrm{CSM}$ is more often seen in patients with more than $30 \%$ of spinal canal stenosis. Clinical manifestations of cervical DDD may be due to either direct cord compression, ischemia due to compression of vascular structures or repeated local trauma to the cord in the presence of cervical disc prolapse. ${ }^{4}$ Early presentations of CSM are gait disturbances, stiffness or weakness of lower limbs and ataxia due to compression of the spinocerebellar tract. Later, with the progression of the disease, patients may have a sensory impairment, posterior column dysfunction, exaggerated reflexes, and sphincter disturbances. Similarly, radicular symptoms include upper limb pain, weakness of intrinsic muscles of hands, wasting of muscles, clumsiness of fine motor skills, and sensory loss. ${ }^{5,6}$ Various grading systems are available for the assessment of CSM patients pre-operatively and post-operatively. One of the valid and reliable scoring systems is the modified Japanese Orthopedic Association scale (mJOA) scoring system. According to mJOA scores patients are graded into mild (15-17), moderate (12-14) and severe myelopathy $(<11){ }^{7}$

Most of the cases of cervical DDD are managed conservatively with analgesics, cervical immobilization, physiotherapy and modification of lifestyle. Surgical treatment is reserved for persistent pain even after conservative treatment and moderate to severe myelopathy. ${ }^{8,9}$ The aim of surgery in single-level cervical degenerative disc disease is the decompression of neural structures and fixation of motion segments using plates and screws. A common surgical option is anterior cervical discectomy and fusion (ACDF) using iliac crest bone graft [2-8]. ACDF was first introduced by Smith and Robinson in 1958 for the treatment of cervical degenerative disc diseases and later on modified by Cloward and, Bailey and Badgley. ${ }^{10,11,12,13,14}$

\section{Materials and Methods}

The objective of the study was to assess the functional outcome following ACDF in single-level cervical degenerative disc disease in terms of improvement in the mJOA scoring system and postoperative complications.

It is a prospective single institutional study conducted in the Department of Neurosurgery, College of Medical Sciences (CMS), Chitwan, Nepal from May 2018 to October 2019 after clearance from the ethical committee
(College of Medical Sciences). Informed consent was taken from patients fulfilling the inclusion criteria after explaining the details of the procedure, outcome, and risks. Patients included in the study were single-level cervical degenerative disc disease with age between 40 to 70 years with progressive neurological deficits, features of cervical spondylotic myelopathy (CSM) and patients with mild grade who failed four weeks of conservative treatment and progressed to moderate or severe grades. Patients with multi-level cervical disc diseases, traumatic cervical disc diseases, coagulopathy and diathesis, multiple comorbidities who were unfit for general anesthesia were excluded from the study.

Detailed history and neurological assessment of enrolled patients were carried out. Cervical spine x-rays: anteroposterior and lateral views were obtained. Magnetic resonance imaging (MRI) scans of the cervical spine were done to assess the level of the degenerative disc disease and the extent of neural compression. Preoperative modified Japanese Orthopedics Association (mJOA) score was obtained. All patients underwent ACDF under general anesthesia.

\section{Procedure:}

A standard anterior cervical discectomy and fusion with right sided approach was done. Transverse skin incision given after pre-operative confirmation of level with fluoroscopy. Dissection was carried out along the medial border of the sternocleidomastoid muscle followed by retraction of carotid sheath laterally and trachea and esophagus medially. The prevertebral fascia and medial border of longus coli muscle were cauterized and dissected. Cloward retractor system was applied. The disc was incised with a surgical blade and discectomy carried out with a curette, pituitary rongeurs, and highspeed diamond drill under the microscope. Posterior longitudinal ligament incised and decompression of nerve root confirmed with a nerve hook. Tricortical bone graft taken from the iliac crest, placed over discectomy site and instrumentation done with titanium plates and screws. In five cases, polyether ether ketone (PEEK) cage packed with osteophytes/bone graft was also used. Then the wound was closed in layers.

Postoperatively, the patient was shifted to the intensive care unit with Philadelphia collar which was continued for six-eight weeks. Suture removal was done on the seventh postoperative day and the patient was discharged. Subsequent follow up was done at four and 12 weeks to assess mJOA score and delayed postoperative complications. Physiotherapy was started on fourth postoperative day in patients with myelopathy. 


\section{Lamichhane et al}

\section{Statistical analysis:}

Statistical analysis was done using the Statistical Package for the Social Sciences version 20 software in descriptive and inferential forms. In the descriptive statistics, Microsoft Word and Excel were used to generate diagrams, graphs, and tables. Descriptive statistics of the quantitative data was presented by frequency, percentage. The difference in means is analyzed by paired $\mathrm{T}$ test. A p-value $<0.05$ was considered statistically significant.

\section{Results}

Total number of patients in our study was 18 with mean age of 57.7 years ranging from 50 to 70 years and standard deviation of 6.78 . Out of 18 patients enrolled in our study, 14 were males (78\%) and 4 were females (22\%).

The most common clinical presentation among these patients was cervical pain with radiculopathy and stiffness/weakness of upper limb in 10 patients followed by cervical pain with radiculopathy and upper limb sensory impairment in 4 patients. Two patients presented with cervical pain with motor and sensory impairment of upper and lower limbs whereas the remaining two had bladder sphincter impairment.

C5-C6 was the most commonly affected level among 12 patients, followed by $\mathrm{C} 4-\mathrm{C} 5$ level in 3 patients. Similarly, two patients presented with $\mathrm{C} 6-\mathrm{C} 7$ and one patient with C3-C4 level involvement.
At the time of presentation, 12 patients $(66.7 \%)$ were in moderate grade, six patients $(33.3 \%)$ in severe grade and none of them were in mild grade of mJOA. At four weeks of post-operative follow-up, 10 patients improved to mild grade, while four patients each were persistent in moderate and severe grades.

During follow-up at three months, 15 patients improved to mild grade while two remained in moderate grade and one patient did not improve and remained persistent in severe grade.

After all statistical analysis using paired T-test to compare the pre-operative status in term of MJOA score with post-operative fourth and $12^{\text {th }}$-week status, the p-value was found to be $0.003(<0.0050)$ which signifies that aforementioned surgery was effective and relatively safe for single-level degenerative cervical disc diseases.

Among 11 patients who presented with motor dysfunction (weakness or tightness of limbs), at the end of 3 months follow-up eight patients improved significantly. Only three out of five patients with sensory impairment showed significant improvement. Similarly, among two patients with bladder dysfunction one showed improvement at the end of 12 weeks follow up.

\section{Post-operative complications:}

One patient developed superficial wound infection which was treated with parenteral antibiotics. Two patients complained of dysphagia and hoarseness of voice which improved gradually within a few weeks with conservative management. However, no mortality was recorded.

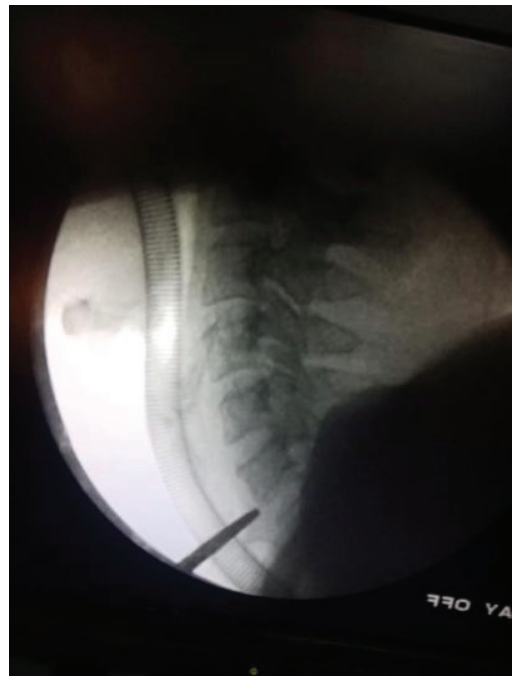

Figure 1: (a) Preoperative and (b) intra-operative fluoroscopic localization

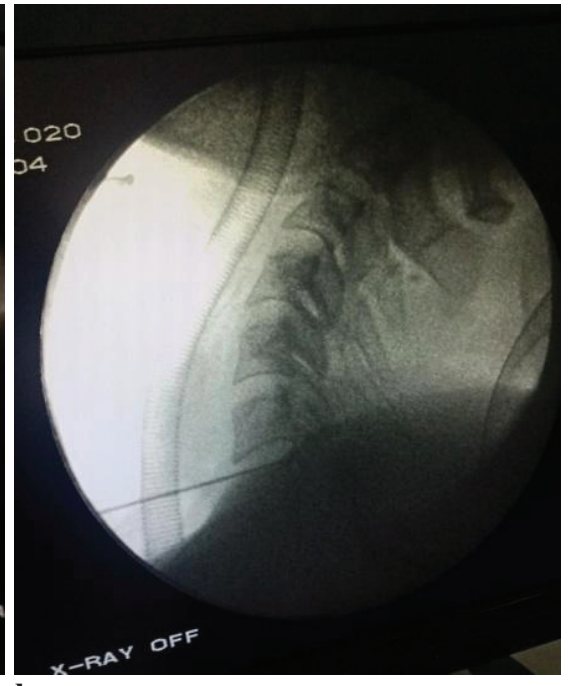

b 
Functional outcome following ACDF in degenerative cervical spine

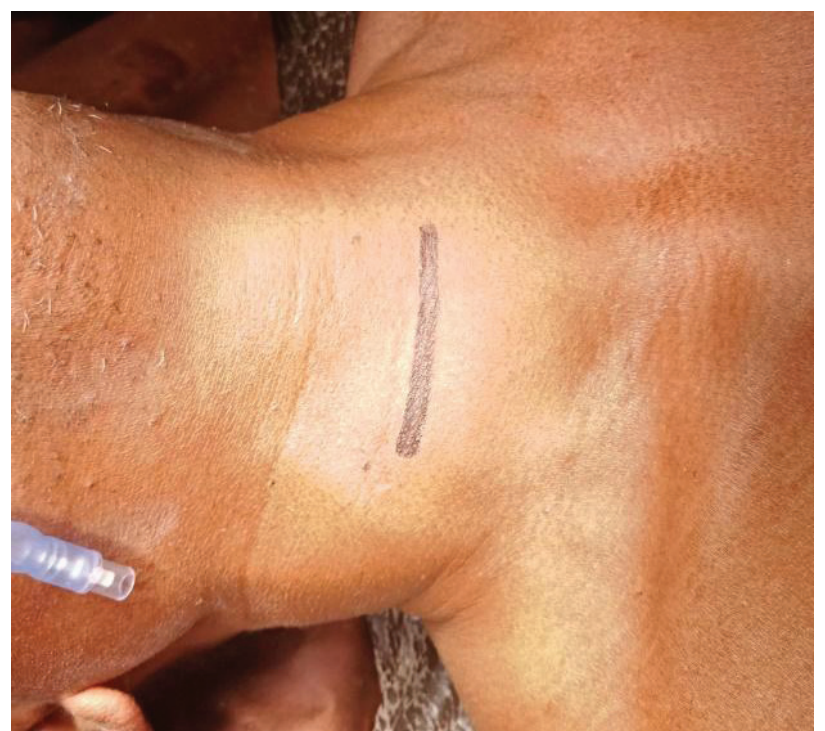

Figure 2: Transverse skin marking prior to incision

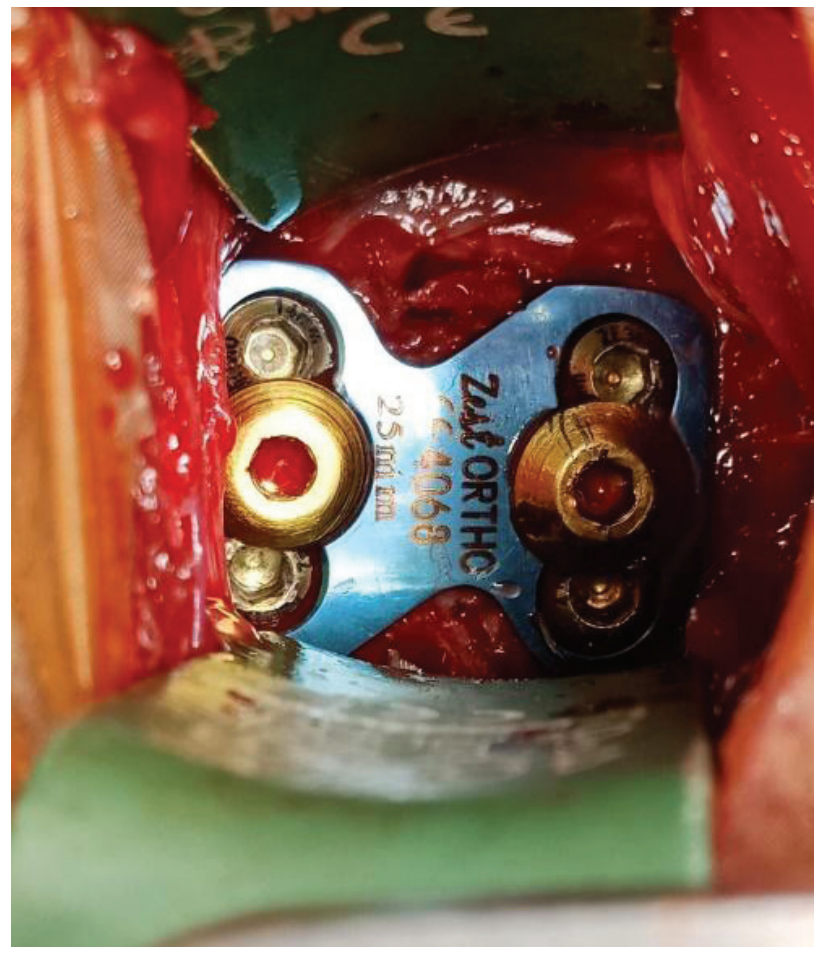

Figure 3: Intra-operative image with plate and screws

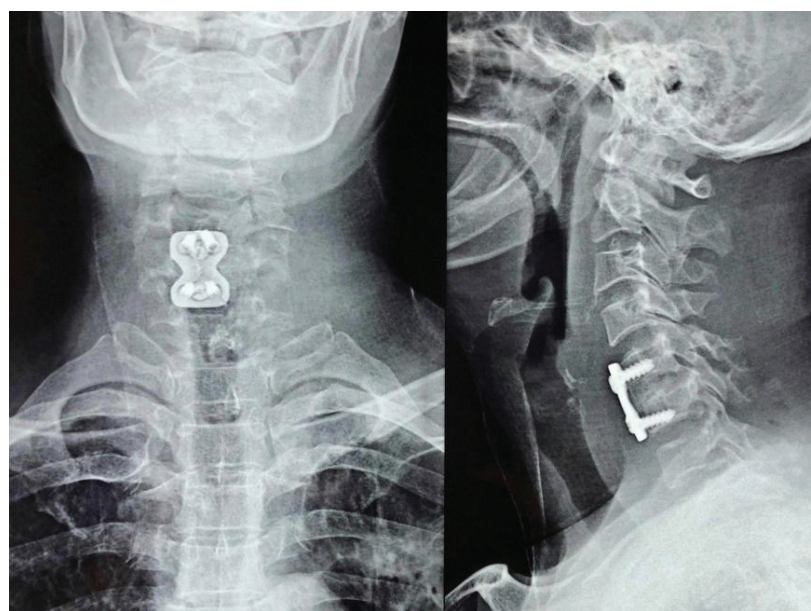

Figure 4: Post-operative Antero-posterior and lateral cervical $X$-rays

\section{Discussion}

Prior to 1950 , almost all cervical spine surgeries were primarily performed via the posterior approach. The anterior approach for cervical spine surgery was initially described in the 1950 s to access esophagus. In 1958, Smith and Robinson applied the anterior approach for a cervical discectomy and interbody fusion using a horseshoe-shaped graft, which was harvested from the iliac crest in patients suffering from degenerative cervical disc diseases. By this approach, the disc was removed from anterior and the space was filled by tricortical iliac bone graft to achieve fusion. ${ }^{13}$

In our study, the age group most commonly affected was between 50-70 years with a mean age of 57.7 years which was comparable to the reports of Azimi et al., who had reported mean age of $54+8.3$ years. ${ }^{15}$ Similarly, mean age in Sharma et al study was 51.07 years with range of 3070 years. ${ }^{16}$ Cervical degenerative disc disease commonly affects people in their late fifties and progresses with the age due to continuous degeneration of intervertebral disc and two dorsal zygapophyseal joints. Degeneration in one of these joints often leads to accelerated degeneration in the adjacent joints. This results in the progression of degeneration. ${ }^{17}$
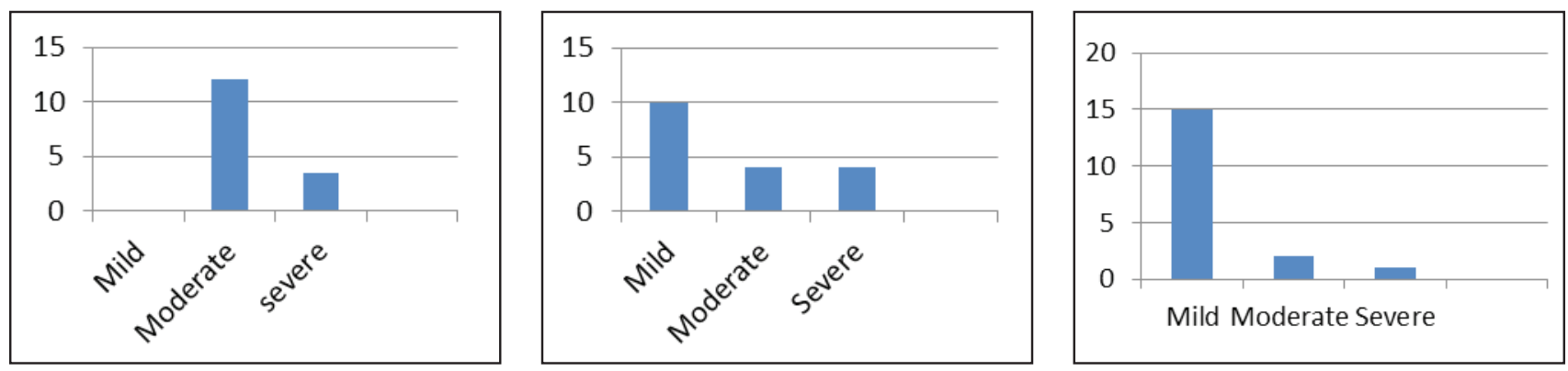

Graph 1: The mJOA grades at presentation, at four weeks post-operative follow-up and at 12 weeks follow-up respectively 
The gender distribution of our study showed male predominance i.e. $78 \%$ male and $22 \%$ female which is comparable to series of Ali et al. and Sharma et al., where predominantly affected patients were males. ${ }^{16,18}$ This gender distribution may be attributed to the differences in the pattern of hospitalization and males seeking treatment earlier than females.

C5-C6 was the most common level affected (66.7\%) followed by C4-C5 (17\%). Sharma et al. in their study found C5-C6 levels most commonly involved (40\%) followed by $\mathrm{C} 6-\mathrm{C} 7$ in $23.3 \%$. Similar results were seen in Kamani et al. study with almost $90 \%$ involvement of the C5-C6 level. C5-C6 and C6-C7 levels are most mobile segments in the cervical spine and are exposed to early degenerative changes compared to other levels. ${ }^{19}$

Our results revealed that after four weeks following surgery there was a significant improvement in mJOA score from severe to moderate and moderate to mild gradually. These improvements were more significant at 12 weeks follow up. One patient from severe category remained static even after surgery. Fehling MG et al. reported that there was a significant improvement in mJOA after one year of surgery. ${ }^{20}$ Kamani et al. reported that all the patients improved to mild category following ACDF surgery after six months follow up. ${ }^{19}$ Our study revealed no significant improvement in two patients out of 18 i.e. one remained in severe and one remained in the moderate category. This may be due to the advanced stage of disease and the presence of other comorbidities affecting the spinal cord and impairing the neurological function of the patient. Another limitation of our study was the short duration of follow up period where there is a chance of incomplete improvement in some patients where it takes more than three months. This was further highlighted by Sharma et al in his study, where he noted statistically significant improvement in symptoms of axial neck pain, radicular arm pain, clumsy hand, and gait disturbances at six months and one year follow up. ${ }^{16}$

Islam and colleagues' study concluded that one or two-level ACDF for spondylotic radiculo-myelopathy was one of the most effective procedures with a rapid return to daily activity and upgrade the quality of life. ${ }^{21}$ But here we excluded all types of multilevel disc diseases and the functional outcome was studied only for single-level degenerative disc disease and the result was comparable to the aforementioned study after three months of surgery.

Hessler and colleagues reported symptomatic improvement in $80 \%$ of patients who underwent ACDF surgery with cervical plating. This is comparable to our study which has an improvement rate of $88.8 \%{ }^{22}$

Yuen J, Whitfield $\mathrm{P}$. reported that with cervical myelopathy, 50 to $80 \%$ of patients improved after surgery, while 50 to $30 \%$ had ongoing or progressive symptoms of radiculopathy and myelopathy. ${ }^{23}$

While analyzing the post-operative complications Liao JC et al. reported dysphonia and hoarseness of voice in one patient which is comparable to our study. ${ }^{24}$ In our study, one out of 18 patients developed dysphonia which recovered within a few weeks. Transient dysphonia following ACDF is mainly due to recurrent laryngeal nerve paresis due to excessive traction or compression during surgery.

Kamani et al. reported one death in the immediate post-operative period from esophageal rupture but such dreadful complication was not revealed in our study. ${ }^{19}$ Rather we had a wound infection in one patient resulting in a longer duration of hospital stay and prolonged course of antibiotics. One patient developed dysphagia which resolved spontaneously within a few days.

\section{Limitations of the study}

While comparing with other international studies the duration of our study with three months follow up period is relatively short. Due to short post-operative follow up long term assessment in terms of improvement couldn't be made. Similarly, the sample size of 18 patients is also relatively small.

\section{Conclusion}

Anterior cervical discectomy and fusion is one of the effective and safe treatments for single-level degenerative cervical disc disease associated with cervical spondylotic myelopathy with minimal complications.

\section{Conflict of Interest: None}

Source(s) of support: None

\section{References}

1. Young WF. Cervical spondylotic myelopathy: a common cause of spinal cord dysfunction in older persons. Am Fam Physician. 2000; 62(5):1064-70. PMID: 10997531.

2. Bednarik J, Kadanka Z, Dusek L, Novotny O, Surelova D, Urbanek I et al. Presymptomatic spondylotic cervical cord compression. Spine (Phila Pa 1976). 2004; 29(20):2260-9. https://doi. org/10.1007/s00586-008-0585-1.

3. Cooper PR. Cervical Spondylotic Myelopathy. Contemp Neurosurg. 1997; 19:1-7. https://doi. org/10.3171/spi.2005.3.3.0253.

4. Levine DN. Pathogenesis of Cervical Spondylotic Myelopathy. J Neurol Neurosurg Psychiatry. 1997; 
62:334-40. https://doi.org/10.1136/jnnp.62.4.334.

5. Emery SE. Cervical spondylotic myelopathy: diagnosis and treatment. J Am Acad Orthop Surg. 2001; 9:376-88. https://doi.org/10.5435/00124635200111000-00003.

6. Celmir de Oliveira Vilaça, Marco Orsini, Marco A. Araujo Leite, Marcos R.G. de Freitas, Eduardo Davidovich, Rossano Fiorelli et al. Cervical Spondylotic Myelopathy: What the Neurologist Should Know. Neurol Int. 2016 Nov 2; 8(4): 6330. https://doi.org/10.4081/ni.2016.6330.

7. Kumbhar Kartik Revanappa and Vedantam Rajshekhar. Comparison of Nurick grading system and modified Japanese Orthopedics Association scoring system in evaluation of patients with cervical spondylotic myelopathy. Eur Spine J. 2011 Sep; 20(9): 1545-51. https://doi.org/10.1007/s00586-0111773-y.

8. Matz PG, Holly LT, Mummaneni PV, Anderson PA, Gro MW, Heary RF et al. Anterior cervical surgery for the treatment of cervical degenerative myelopathy. J Neurosurg: Spine. 2009; 11:170-3. https://doi. org/10.3171/2009.3.SPINE08724.

9. Matz PG, Holly LT, Gro MW, Vresilovic EJ, Anderson PA, Heary RF et al. Indications for anterior cervical decompression for the treatment of cervical degenerative radiculopathy. J Neurosurg: Spine. 2009; 11:174-82. https://doi. org/10.3171/2009.3.SPINE08720.

10. Bednarik J, Kadanka Z, Dusek L, Novotny O, Surelova D, Urbanek I et al. Presymptomatic spondylotic cervical cord compression. Spine (Phila Pa 1976). 2004; 29(20):2260-9. https://doi.org/10.1097/01. brs.0000142434.02579.84.

11. Nikolaidis I, Fouyas IP, Sandercock PA, Statham PF. Surgery for cervical radiculopathy or myelopathy. Cochrane Database Syst Rev. 2010;(1):CD001466. https://doi.org/10.1002/14651858.CD001466.pub3.

12. Bailey RW, Badgley CE. Stabilization of the cervical spine by anterior fusion. Am J Orthop. 1960; 42-A: 565-94. PMID: 13848906.

13. Smith GW, Robinson RA. The treatment of cervical spine disorders by anterior removal of the intervertebral disc and interbody fusion. J Bone Joint Surg.1958; 40:607-24. PMID: 13539086.

14. Cloward RB. The anterior approach for removal of ruptured discs. J Neurosurg. 1958; 15:602-17. https://doi.org/10.3171/spi.2007.6.5.496.

15. Azimi P, Shahzadi S, Benzel EC, Montazari A. Functional evaluation using the modified Japanese
Orthopedic Association score (mJOA) for cervical spondylotic myelopathy disease by age, gender, and type of disease. J Inj Violence Res. 2012; 4(3 Suppl 1):42.

16. Sharma A, Dhake M, Singh V, Natraj B, Mahajan $\mathrm{R}$, Kamble P et al. Study of Functional Outcome of Anterior Cervical Decompression and Fusion Using Tricortical Iliac Bone Graft for Degenerative Cervical Spondylotic Myelopathy with Modified Japanese Orthopedic Association Score. J Spine.2015; 4:255. https://doi.org/10.4172/2165-7939.1000255.

17. Ritchie JH, Fahrni WH. Age changes in lumbar intervertebral discs. Can J Surg. 1970; 13(1):65-7. PMID: 5414331.

18. Ali MI, Ahsan K, Awwal MA, Khan RH, Akhond S, Das KP, et al. Treatment of cervical disc prolapse by anterior cervical discectomy fusion and stabilization with plating. Mymensingh Med J. 2009; 18(2):22631. PMID: 19623152.

19. Kamani MM, Ballal A, Shetty V, Rai HR, Hegde D. A Prospective Study of the Functional Outcome of Anterior Cervical Discectomy with Fusion in Single Level Degenerative Cervical Disc Prolapse. Clin Diagn Res. 2016; 10(5):RC01-4. https://doi. org/10.7860/JCDR/2016/16961.7709.

20. Fehlings MG, Wilson JR, Kopjar B, Yoon ST, Arnold PM, Massicotte EM, et al. Efficacy and safety of surgical decompression in patients with cervical spondylotic myelopathy: results of the AO Spine North America prospective multi-center study. J Bone Joint Surg Am. 2013; 95(18):1651-8. https:// doi.org/10.2106/JBJS.L.00589.

21. Islam MA, Habib MA, Sakeb N. Anterior Cervical Discectomy, Fusion and stabilization by plate and screw-early experience. Bangladesh Med Res Counc Bull. 2012; 38:62-6. https://doi.org/10.3329/ bmrcb.v38i2.12884.

22. Hessler C, Boysen K, Westphal M, Regelsberger J. Functional and radiological outcome after ACDF in 67 cases. Z Orthop Unfall. 2011; 149(6):683-7. https://doi.org/10.1055/s-0030-1270843.

23. Yuen J, Whitfield P. Anterior cervical discectomy and fusion (ACDF) for degenerative cervical diseases Six decades on. ACNR. 2017; 17(1); 5-10.

24. Liao JC, Niu CC, Chen WJ, Chen LH. Polyetheretherketone (PEEK) cage filled with cancellous allograft in anterior cervical discectomy and fusion. Int Orthop. 2008; 32(5):643-8. https://doi. org/10.1007/s00264-007-0378-x. 